\title{
Genomic selection for tolerance to heat stress in Australian dairy cattle
}

\author{
Thuy T. T. Nguyen, ${ }^{* 1}$ Phil J. Bowman, ${ }^{*}$ Mekonnen Haile-Mariam, ${ }^{*}$ Jennie E. Pryce, ${ }^{\star} \dagger$ and Benjamin J. Hayes ${ }^{*} \dagger$ \\ *BioSciences Research Division, Department of Economic Developments, Jobs, Transport and Resources, \\ and Dairy Futures Cooperative Research Centre, Agribio, 5 Ring Road, Bundoora, Victoria 3083, Australia \\ †La Trobe University, Bundoora, Victoria 3083, Australia
}

\begin{abstract}
Temperature and humidity levels above a certain threshold decrease milk production in dairy cattle, and genetic variation is associated with the amount of lost production. To enable selection for improved heat tolerance, the aim of this study was to develop genomic estimated breeding values (GEBV) for heat tolerance in dairy cattle. Heat tolerance was defined as the rate of decline in production under heat stress. We combined herd test-day recording data from 366,835 Holstein and 76,852 Jersey cows with daily temperature and humidity measurements from weather stations closest to the tested herds for test days between 2003 and 2013. We used daily mean values of temperaturehumidity index averaged for the day of test and the 4 previous days as the measure of heat stress. Tolerance to heat stress was estimated for each cow using a random regression model with a common threshold of temperature-humidity index $=60$ for all cows. The slope solutions for cows from this model were used to define the daughter trait deviations of their sires. Genomic best linear unbiased prediction was used to calculate GEBV for heat tolerance for milk, fat, and protein yield. Two reference populations were used, the first consisted of genotyped sires only $(2,300$ Holstein and 575 Jersey sires), and the other included genotyped sires and cows (2,189 Holstein and 1,188 Jersey cows). The remainder of the genotyped sires were used as a validation set. All animals had genotypes for 632,003 single nucleotide polymorphisms. When using only genotyped sires in the reference set and only the first parity data, the accuracy of GEBV for heat tolerance in relation to changes in milk, fat, and protein yield were $0.48,0.50$, and 0.49 in the Holstein validation sires and $0.44,0.61$, and 0.53 in the Jersey validation sires, respectively. Some slight improvement in the accuracy of prediction was achieved when cows were included
\end{abstract}

Received April 8, 2015.

Accepted December 21, 2015.

${ }^{1}$ Corresponding author: thuy.nguyen@ecodev.vic.gov.au in the reference population for Holsteins. No clear improvements in the accuracy of genomic prediction were observed when data from the second and third parities were included. Correlations of GEBV for heat tolerance with Australian Breeding Values for other traits suggested heat tolerance had a favorable genetic correlation with fertility $(0.29-0.39$ in Holsteins and 0.15-0.27 in Jerseys), but unfavorable correlations for some production traits. Options to improve heat tolerance with genomic selection in Australian dairy cattle are discussed.

Key words: heat tolerance, milk production, temperature-humidity index, genomic selection

\section{INTRODUCTION}

Increases in ambient temperature, humidity, air flow, and radiation above a comfort threshold are known to lead to heat stress in dairy cattle (Armstrong, 1994). Dairy cows respond to heat stress in several ways, including reduced feed intake (Beede and Collier, 1986), lower milk yield and milk quality (Bohmanova et al., 2007; Hammami et al., 2013), and compromised fertility (Ravagnolo and Misztal, 2002; Haile-Mariam et al., 2008). Collectively, these responses increase management costs and result in loss of income (St-Pierre et al., 2003).

Heat stress in cows can be relieved by providing shades, fans, and sprinklers (Moran, 2005). However, this may not be practical, or particularly effective in pastoral systems common in Australia, New Zealand, and some other countries. A supplementary strategy would be selection for improved heat tolerance, which would have cumulative and permanent effects. Several authors have demonstrated that the extent of decline in milk production with increasing heat stress varies between animals and is a lowly to moderately heritable trait (Ravagnolo and Misztal, 2000; Bernabucci et al., 2014). This trait could be used as an indicator trait for heat tolerance. Whereas selection based on phenotype and pedigree could be applied for this trait, rates of genetic gain are likely to be slow given the heritability of the trait and long generation interval associated with 
traditional selection in dairy cattle. Genomic selection is an attractive alternative, allowing young bulls (and heifers) to be selected on their heat tolerance genomic estimated breeding value (GEBV) as well as on other traits. In practice, as dairy bulls are increasingly selected for breeding based on GEBV (for a range of traits) rather than progeny testing, a GEBV for heat tolerance is necessary if this trait is to be considered in selection decisions. A further advantage of implementing a GEBV for heat tolerance is that because nearly all young dairy bulls are already genotyped, the marginal cost of the additional GEBV is very small. Accelerating the rate of genetic gain for heat tolerance in some dairy regions will become more and more important as the incidence of heatwave events rises to enable adaptation to these future climates (CSIRO and BoM, 2014).

The main challenges for developing a GEBV for heat tolerance are assembly of a reference population of genotyped animals with phenotypes for heat tolerance, choice of the phenotype itself, and the model used to incorporate genomic information. With regard to choice of phenotype, several studies have used temperaturehumidity indices (THI) as an indicator of heat load and combined these data with test day records for milk yield traits to estimate genetic components of heat tolerance. Ravagnolo and Misztal (2000) reported an increase in additive genetic variance for heat tolerance as THI exceeded a thermoneutral threshold. Genetic variance for heat tolerance is also reported to increase with subsequent lactations (Aguilar et al., 2009; Bernabucci et al., 2014). In Australian dairy cattle, Hayes et al. (2003) demonstrated that protein production began to decline at THI of 60 (e.g., daily average temperature of $20^{\circ} \mathrm{C}$ and humidity of $45 \%$ ). The advantage of using the decline in milk production as a phenotype for heat tolerance is that the phenotype can be collected on a very large scale by combining weather station data and herd recording data. This allows a large reference population to be assembled for estimating GEBV, as daughter trait deviations (DTD) can be calculated for this trait for nearly all genotyped sires.

To estimate variance components for heat tolerance in dairy cattle, many studies have assumed that all animals have a common comfort threshold and that production declines when the THI exceeds the threshold. A more realistic model was proposed by Sánchez et al. (2009), who estimated a threshold and slope for each animal. Those authors reported that the threshold and slope have large genetic components; however, the genetic correlation between them is 0.95 (Sánchez et al., 2009), indicating that an animal with a higher threshold of heat stress would also have a lower rate of decline and vice versa. Sánchez et al. (2009) suggested that selection on one component of heat tolerance would lead to favorable response for the other. In addition, as Sánchez et al. (2009) pointed out, the model that inferred both threshold and slope required fixing the mean threshold to a previously estimated value to obtain sensible estimates. Therefore, a simple model assuming a constant threshold at which THI affects milk production across animals, but different slopes, could result in reasonable estimates of breeding value that capture most of the genetic variation for heat tolerance. The reliabilities calculated from such a model may be biased, however, and this would have to be addressed in routine evaluations.

In dairy cattle breeding, many traits are selected simultaneously using selection index theory (Hazel, 1943), and most modern selection indices include a combination of production and health and fitness traits (Miglior et al., 2005). To include heat tolerance in a selection index, the accuracy of selection and correlations with other traits would be required in addition to the effect of the trait on net profitability of dairy farms (economic value).

Our aim was to assess the accuracy of GEBV that can be achieved for heat tolerance in Australian Holstein and Jersey cattle. To do this, we merged herd test-day records of production traits with weather data and derived the change in production for cows using a random regression model. The slope solution for cows from this model were used for DTD, which were used as the sire-pseudo phenotypes to be fitted in a genomic BLUP model. We also investigated the correlation of heat tolerance with other traits as the first step toward including this trait in selection indices for dairy cattle in regions where heat stress occurs.

\section{MATERIALS AND METHODS}

The Australian dairy industry is mainly pasturebased, and on most farms dairy cattle do not have access to barns during high-heat load periods. Therefore, it is reasonable to assume that the weather conditions for a herd location are likely to be similar to the nearest public weather station on the same day and time. Such an approach of combining field performance with public weather data has been extensively used in studies related to heat stress in many regions (Bohmanova et al., 2007; Aguilar et al., 2009), including Australia (Hayes et al., 2003; Haile-Mariam et al., 2008).

\section{Climate Data}

Climate data including hourly measures of dry bulb temperature and relative humidity were obtained from 
the Bureau of Meteorology (Melbourne, Australia) for all weather stations in Australia from 2003 to 2013. Only stations that had less than $5 \%$ missing records were used. Hourly THI was calculated as:

$$
\mathrm{THI}=\mathrm{T}_{\mathrm{db}}+\left(0.36 \mathrm{~T}_{\mathrm{dp}}\right)+41.2,(\text { Yousef, 1985) }
$$

where $\mathrm{T}_{\mathrm{db}}=$ hourly dry bulb temperature $\left({ }^{\circ} \mathrm{C}\right) ; \mathrm{T}_{\mathrm{dp}}$ is dew point temperature $\left({ }^{\circ} \mathrm{C}\right)$ and $\mathrm{T}_{\mathrm{dp}}=(237.3 \mathrm{~b}) /(1.0$ $-\mathrm{b})$, where $\mathrm{b}=\left[\log (\mathrm{RH} / 100.0)+\left(17.27 \mathrm{~T}_{\mathrm{db}}\right) /(237.3\right.$ $\left.\left.+\mathrm{T}_{\mathrm{db}}\right)\right] / 17.27$, and $\mathrm{RH}=$ relative humidity. The daily average of the THI was calculated for each weather station by averaging hourly values over $24 \mathrm{~h}$. Earlier investigations in Australia have shown that THI on the test day and 1,2,3, and $4 \mathrm{~d}$ before the test day had significant effects on herd-test day milk production yields (Hayes et al., 2003). Therefore, we averaged the THI of the test day and 1,2,3, and $4 \mathrm{~d}$ before the test day to create composite THI values corresponding to each herd test day, which is hereafter designated as just THI.

\section{Phenotypes}

A total of 6.8 million, 4.8 million, and 3.0 million test-day records for first, second, and third lactations between 2003 and 2013, respectively, for milk, protein, and fat yields were extracted from the Australian Dairy Herd Improvement Scheme database for Holstein and Jersey cows. Records were filtered for the first parity data using the following criteria: (1) tests before $6 \mathrm{~d}$ in lactation, or after $305 \mathrm{~d}$ were excluded, (2) herd test dates that had records from fewer than 30 Holstein or 10 Jersey cows, or fewer than 3 sires in each breed were eliminated, (3) sires that had daughters in fewer than 3 herds and herds that used less than 3 sires were excluded, and (4) only cows with at least 5 records were used in the analyses. The number of cows in the filtered data set was 366,835 Holsteins and 76,852 Jerseys (Table 1) and the corresponding number of records were $2,503,248$ and 563,906, respectively. Records in the second and third parities were selected for cows present in the first parity data set.

\section{Merging Climate and Phenotype Data}

Pairwise distances (measured in $\mathrm{km}$ ) were calculated between milk-recording dairy herds and weather stations using geographic coordinates. Herds' geographic coordinates are centroid longitude and latitude of their postal codes. Climate data applied to a herd were from either the nearest station, or a station which had less than $1 \%$ missing records and its distance to the herd was not greater than 1.5 times of that of the nearest station. In total, we matched 105 weather stations to 1,762 Holstein and 519 Jersey dairy herds (Figure 1). The 5th, 25th, 50th, 75th, and 95th percentiles of distances between weather stations and herds were 4, 13, 23,37 , and $60 \mathrm{~km}$. A summary of the final data set is presented in Table 1 and Figure 2.

\section{Genotypes}

A total of 2,735 Holstein and 710 Jersey sires were genotyped. Illumina Bovine High-Density genotypes (777,963 SNP markers; Illumina, San Diego, CA) were available for 1,620 of the Holstein sires and 125 of the Jersey sires. For all other sires, and 2,189 Holstein and 1,188 Jersey cows, 50K (56,430 SNP) genotypes were available. After quality control, carried out as described by Erbe et al. (2012) and removal of nonpolymorphic SNP, 632,003 SNP remained for animals genotyped at high density and 43,425 SNP remained for animals genotyped at the lower density. All animals genotyped at the lower density had genotypes imputed to the higher-density SNP panel using BEAGLE 3 (Browning and Browning, 2009).

\section{Statistical Methods}

All statistical analyses were undertaken separately for Holsteins and Jerseys. Two options were considered: (1) using only data from the first parity and (2) using combined data from the first, second, and third parities. Mixed linear models were used to fit the data with variance components estimated by residual maximum likelihood in ASREML (Gilmour et al., 2009).

Table 1. Characteristics of the data sets used in the present study

\begin{tabular}{|c|c|c|c|c|c|c|}
\hline \multirow[b]{2}{*}{ Data } & \multicolumn{3}{|c|}{ Holstein } & \multicolumn{3}{|c|}{ Jersey } \\
\hline & 1st parity & 2nd parity & 3rd parity & 1st parity & 2nd parity & 3rd parity \\
\hline Number of herd test dates & 85,714 & 61,481 & 52,520 & 26,441 & 20,393 & 17,197 \\
\hline Number of cows & 366,835 & 275,356 & 176,174 & 76,852 & 59,266 & 40,356 \\
\hline Number of sires & 8,586 & 7,796 & 6,623 & 2,828 & 2,530 & 2,143 \\
\hline Average number of cows per test date & 42 & 29 & 21 & 28 & 20 & 16 \\
\hline
\end{tabular}




\section{Genetic Parameters}

A random regression model was used to derive the response of milk, fat, and protein yields of the cows to changes in THI (i.e., the slope of the regression), as follows:

$$
\begin{aligned}
& y_{i j k l m}=\mu+H T D_{i}+Y S_{j}+P A R_{k}+\sum_{n=1}^{3} A_{n} X_{n} \\
& +\sum_{n=1}^{8} P A R_{k} D_{n} Z_{n}+\sum_{n=1}^{2} S T G_{l} T_{n} S_{n}+\sum_{n=0}^{1} C_{m n} W_{n}+e_{i j k l m},
\end{aligned}
$$

[model 1] where $y_{i j k l m}$ is yield of milk in liters, fat in $\mathrm{kg} \times 100$ or protein in $\mathrm{kg} \times 100$ from the $i$ th herd test day, $j$ th year season of calving, and $m$ th cow in the $l$ th stage of her $k$ th lactation; $\mu$ is the intercept; $H T D_{i}$ is the effect of the $i$ th herd test day; $Y S_{j}$ is the effect of the $j$ th year season of calving; $P A R_{k}$ is the effect of the $k$ th parity; $X_{n}$ is the $n$ th-order orthogonal polynomial corresponding to age on day of test; $A_{n}$ is a fixed regression coefficient of milk, fat, or protein yield on age at test; $Z_{n}$ is the $n$ thorder orthogonal polynomial corresponding to DIM at test; $D_{n}$ is a fixed regression coefficient of milk, fat, or protein yield on DIM; $S T G_{l}$ is the effect of the lth stage

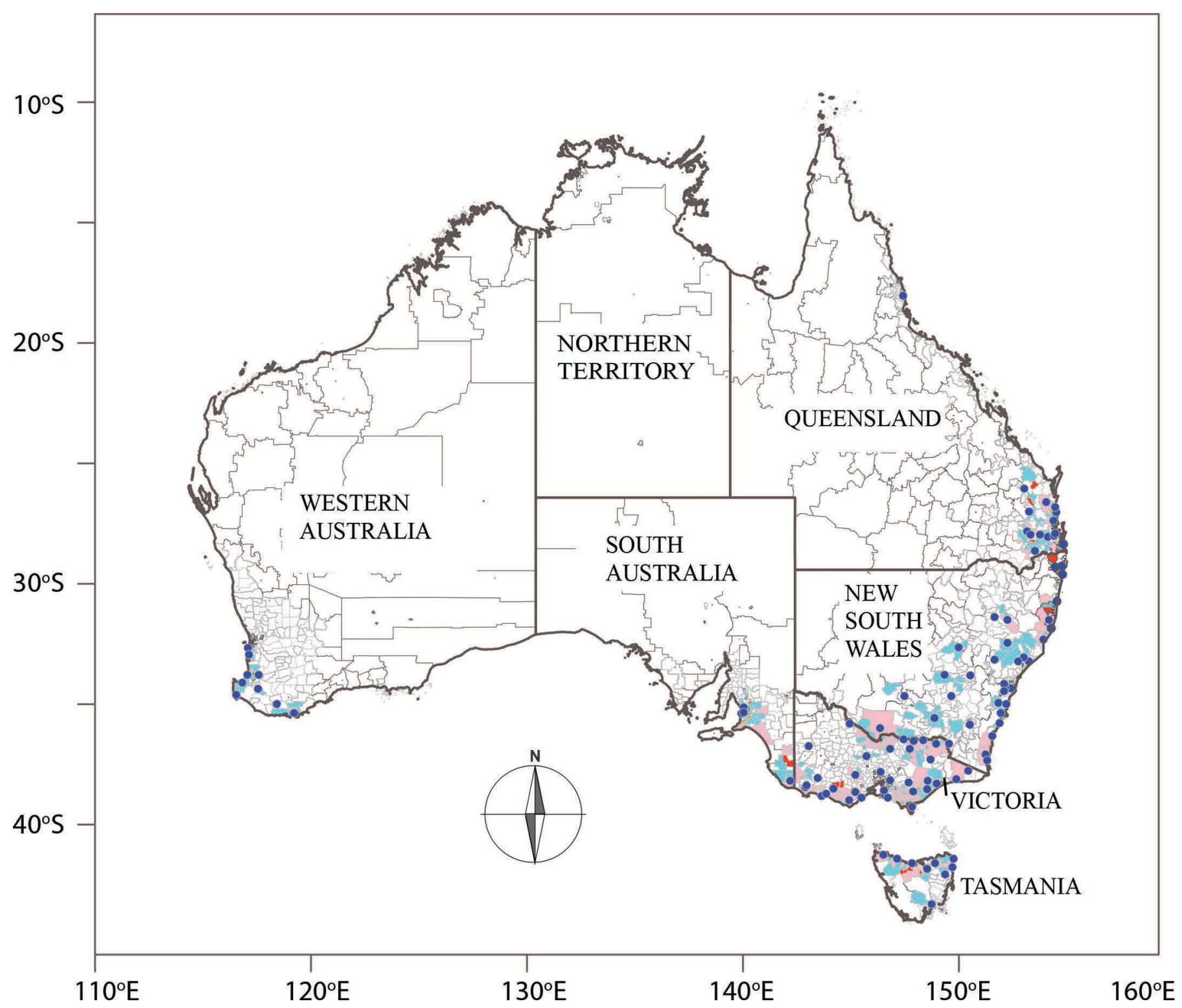

Figure 1. Locations of automatic weather stations and dairy herds for which climate and production data were used in the present study. Blue dots represent 105 weather stations. Pink, cyan, and red areas represent postcodes where both Holstein and Jersey herds, only Holstein herds, and only Jersey herds were located, respectively. 
of lactation (early lactation: DIM $\leq 70$, mid lactation: $70<\mathrm{DIM} \leq 140$, late lactation: $140<\mathrm{DIM} \leq 305) ; T_{n}$ is the $n$ th-order orthogonal polynomial corresponding to THI; $S_{n}$ is a fixed regression coefficient of milk, fat, or protein yield on THI; $C_{m n}$ is a random regression coefficient on heat load index for the $m$ th cow; $W_{n}$ is either the intercept $(n=0)$ or slope solution $(n=1)$ for heat load index for cows; and $e_{i j k l m}$ is the vector of residual effects. In this random regression model, we set the threshold of THI $=60$ following Hayes et al. (2009; i.e., all THI values below 60 were set to 60 ); this threshold was equivalent to daily average temperature of $20^{\circ} \mathrm{C}$ and humidity of $45 \%$.

Error variances were estimated for 10 intervals over the lactation (DIM $=5-30,31-60,61-90,91-120$, 121-150, 151-180, 181-210, 211-240, 241-270, and 271-300). The following (co)variance structure was assumed for model 1 :

$$
\begin{gathered}
\operatorname{var}(\mathrm{C})=\operatorname{var}\left[\begin{array}{c}
c_{0} \\
c_{1}
\end{array}\right]=\left[\begin{array}{ccc}
\mathbf{I} \sigma^{2} c_{0} & \mathbf{I} \sigma c_{0}, c_{1} \\
\mathbf{I} \sigma c_{0}, c_{1} & \mathbf{I} \sigma^{2} c_{1}
\end{array}\right], \\
\operatorname{var}(\mathbf{e})=\operatorname{var}\left[\begin{array}{c}
e_{1} \\
e_{2} \\
\vdots \\
e_{p}
\end{array}\right]=\left[\begin{array}{cccc}
\sigma^{2} e_{1} & 0 & 0 & 0 \\
0 & \sigma^{2} e_{2} & 0 & 0 \\
0 & 0 & \ddots & 0 \\
0 & 0 & 0 & \sigma^{2} e_{p}
\end{array}\right],
\end{gathered}
$$

where $c_{0}$ and $c_{1}$ represent the intercept and slope of cows; $\operatorname{var}(\mathrm{C})$ is a $2 \times 2 \mathrm{co}$ (variance) matrix with I as an identity matrix, and $\sigma^{2} \mathrm{c}_{0}, \sigma \mathrm{c}_{0}, \mathrm{c}_{1}, \sigma \mathrm{c}_{0}, \mathrm{c}_{1}, \sigma^{2} \mathrm{c}_{1}$ represent the genetic (co)variance of random regression coefficients; and $\operatorname{var}(\mathbf{e})$ is a $10 \times 10$ error matrix when data from only the first parity were used $(p=10)$ or a $30 \times$ 30 error matrix when data from 3 parities were used ( $p$ $=30,3 \times$ the 10 DIM intervals above per parity).

Sire sensitivity to milk, protein, and fat yields of cows to changes in THI were obtained using the following model:

$$
\mathbf{y}_{i}=\mu+\operatorname{SIRE}_{i}+\mathbf{e}_{i}, \quad[\text { model } 2]
$$

where $\mathbf{y}_{i}$ is a vector of slope value for cows (obtained from model 1) of the $i$ th sire; $\mu$ is the intercept; $\operatorname{SIRE}_{i}$ is the effect of the $i$ th sire on cow slope $\sim N\left(0, \sigma_{s}^{2}\right)$, where $\sigma_{s}^{2}$ is the sire variance; and $\mathbf{e}_{i}$ is the vector of residuals $\sim N\left(0, \mathbf{I} \sigma_{e}^{2}\right)$, where $\mathbf{I}$ is identity matrix and $\sigma_{e}^{2}$ is residual variance. Note that the sire effect is half of the sire value. The model is simplistic regarding the estimate of sire variance (as it did not include pedigree, which is appropriate for deriving DTD), therefore the estimate of heritability for heat tolerance of derived by multiplying the sire variance (from model 2) by 4 should be treated cautiously and viewed as only an approximation. The solutions for sire effects resulted from this model are actually similar to DTD. a) Holsteins
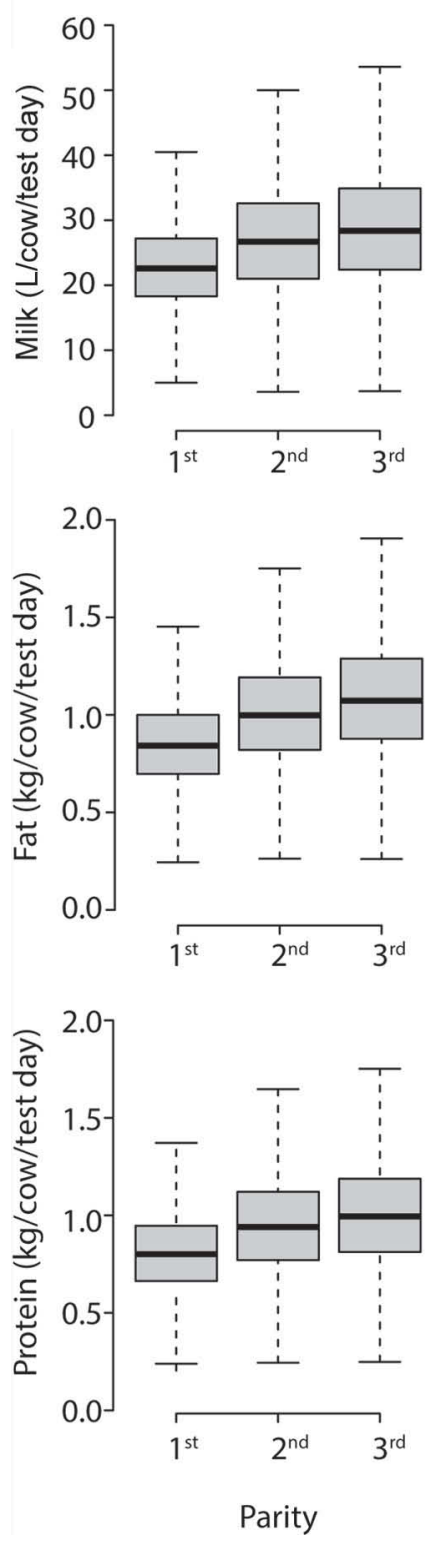

b) Jerseys
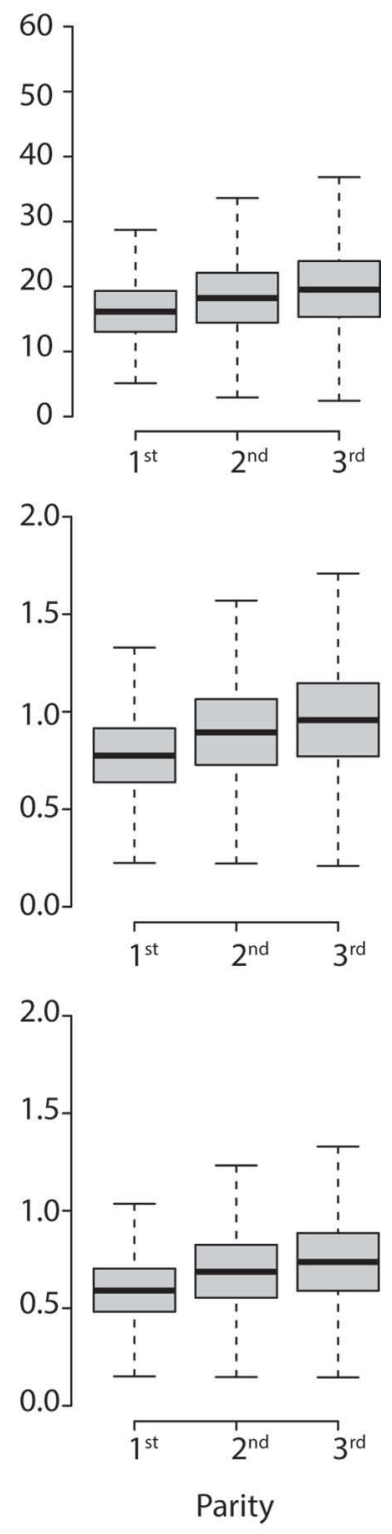

Figure 2. Boxplots presenting distribution of milk, fat, and protein yield of the first, second, and third parities in a) Holsteins and b) Jerseys. The ends of the whiskers of each boxplot represent minimum and maximum of the data, the top and bottom of the box are the first and the third quartiles, and the bold band is the median. 


\section{GEBV}

To estimate genomic breeding values for the sensitivity of sires to THI, as reflected by changes in milk, fat, and protein yields of cows, the following genomic BLUP model was used to fit the data:

$$
\mathbf{y}=\mu+\mathbf{Z g}+\mathbf{e}, \quad[\text { model } 3]
$$

where $\mathbf{y}$ is a vector of sire slope values (solution for $\mathrm{SIRE}_{i}$ obtained from model 2); $\mu$ is the intercept; $\mathbf{Z}$ is a design matrix relating records to genomic breeding value of animals; $\mathbf{g}$ is a vector of genomic breeding values $\sim N\left(0, \mathbf{G R M} \sigma_{g}^{2}\right)$, where $\mathbf{G R M}$ is the genomic relationship matrix and $\sigma_{g}^{2}$ is the genomic variance; and $\mathbf{e}$ is a vector of random residuals $\sim N\left(0, \mathbf{I} \sigma_{e}^{2}\right)$, and $\sigma_{e}^{2}$ is residual variance. The genomic relationship matrix was constructed among all genotyped individuals following Yang et al. (2010). This method standardizes the genotype calls $\left(x_{i j}\right)$ that have mean $=0$ and variance $=1$ by the transformation

$$
\mathrm{z}=\left(x_{i j}-2 p_{i}\right) /\left[2 p_{i}\left(1-p_{i}\right)\right]^{1 / 2},
$$

in which $x_{i j}$ are genotypes of the $i$ th SNP of the $j$ th sire, scored as 0 or 2 for homozygotes and 1 for heterozygotes, and $p_{i}$ is the allele frequency of the $i$ th SNP.

The proportion of variance of DTD explained by SNP was calculated as the genetic variance from the genomic relationship matrix divided by total variance obtained from model 3 . To assess the accuracy of using GEBV to predict heat tolerance in each breed, the sires were split into a reference and a validation populations. These populations were split by age, with sires born before 2005 included in the reference population $(\mathrm{n}=$ $2,300)$ and sires born in or after 2005 placed in the validation population $(\mathrm{n}=435)$ for Holsteins; sires born before 2004 were included the reference population (n $=575$ ) and sires born in or after 2004 were placed in the validation population $(\mathrm{n}=135)$ for Jerseys. Sires that are paternal half-sibs were placed in either the reference set or the validation set. The phenotypes of the validation sires (i.e., solution for sires obtained from model 2) were never used in model 3.

In some analyses, genotyped cows were used in the reference population as well as reference sires, and in this case cows that were daughters of validation bulls were excluded from the analyses. A similar model to model 3 was fitted to the reference data, but in this case the difference in residual variances for bull and cow phenotypes were taken into account, where the vector of random residual $\mathbf{e} \sim N\left(0, \mathbf{W} \sigma_{e}^{2}\right)$, where $\mathbf{W}$ is the diagonal matrix as $\operatorname{diag}\left(1 / w_{i}\right)$, with $w_{i}$ as the weighting coefficient for the $i$ th animal. Weighting coefficients were calculated differently for bulls and cows following Garrick et al. (2009), as follows:

$$
\begin{gathered}
w_{i}(\text { bulls })=\frac{1-h^{2}}{c h^{2}+\frac{4-h^{2}}{p}}, \\
w_{i}(\text { cows })=\frac{1-h^{2}}{c h^{2}\left[\frac{1+(n-1) t}{n}-h^{2}\right]},
\end{gathered}
$$

where $h^{2}$ is the proportion of additive variance of cow slope, $c$ is the proportion of variance not explained by SNP $(c=0.2), p$ is the effective number of daughters, $t$ is the repeatability of the trait, and $n$ is the number of repeat records. In this case $n=1$ and, hence:

$$
w_{i}(\mathrm{cows})=\frac{1-h^{2}}{1+(c-1) h^{2}} .
$$

The accuracy of genomic prediction was taken as the correlation of the GEBV and the slope solution for the validation sires (from model 2), divided by the square root of the proportion of variance of DTD explained by SNP obtained from model 3.

\section{Correlations Between Heat Tolerance GEBV with EBV of Other Traits}

To estimate genetic correlations between traits, for each breed, we randomly split the genotyped sire population into 3 subsets. Animals which were paternal halfsibs were placed in the same subset. Two of the subsets were combined to form a reference population and the third subset was used as a validation sample. Data were then fitted using model 3 for each set of the 3 reference data sets. The GEBV predicted for all 3 validation sets were then correlated with the Australian Breeding Value (ABV) of the same sires for other traits, such as milk yield, protein yield, fat yield, fat percent, protein percent, residual survival, cell count, fertility, and feed saved. The fertility ABV is expressed as 6-wk in-calf rate and derived from a 5-trait model that includes calving interval, lactation length, first service nonreturn rate, days to first service, and pregnancy (HaileMariam and Pryce, 2012). Feed saved is a newly added trait expressed as the number of kilograms of feed that are saved from improvements in residual feed intake 
and maintenance derived from BW (Pryce et al., 2015). Both the feed saved and fertility breeding values are included in the Australian national selection indices [Balanced Performance Index (BPI), Health Weighted Index, and Type Weighted Index]. The sire ABV were accessed from Australian Dairy Herd Improvement Scheme in February 2015. Only ABV of sires with reliabilities of production traits that were greater than $75 \%$ and born since 1990 were used. A total of 2,357 Holstein and 576 Jersey bulls included in this analysis.

To correct the correlations for reliabilities of the breeding values, we applied the method of Calo et al. (1973) to approximate genetic correlations between heat tolerance and other traits:

$$
\hat{r}_{h, t}=\frac{\sqrt{\left(\sum_{i=1}^{n} R E L_{h i}\right)\left(\sum_{i=1}^{n} R E L_{t i}\right)}}{\sum_{i=1}^{n}\left(R E L_{h i} \times R E L_{t i}\right)} r_{h, t},
$$

where $\hat{r}_{h, t}$ is the approximate genetic correlation between heat tolerance and each of the traits listed above; $R E L_{h i}$ and $R E L_{t i}$ represent reliabilities of heat tolerance and the other trait for sire $i$, respectively; and $r_{h, t}$ represents the correlation between heat tolerance GEBV and the other trait ABV.

\section{Response to Selection for Heat Tolerance}

Responses to selection for heat tolerance were calculated as the direct response to selection that could be achieved in a 4-pathway breeding scheme that considered heat tolerance (Lush, 1945). We used the following equation to calculate response to selection for heat tolerance:

$$
R_{H T}=\frac{\sum_{n=1}^{4} i_{n}}{\sum_{n=1}^{4} L_{n}} r \sigma_{H T},
$$

where $R_{H T}$ is the response to selection per generation per unit of THI and $i_{n}$ is the selection intensity for each of the selection pathways: (1) sires of sires, (2) sires of cows, (3) dams of sires, and (4) dams of cows. We assumed the percentage of animals selected in each of the pathways was $10,30,2.4$, and $100 \%$; therefore, $i_{1}, i_{2}, i_{3}$, and $i_{4}$ were $1.16,1.75,2.36$, and 0.00 , respectively. We also assumed a generation interval of $2.5 \mathrm{yr}$ for genomically selected bulls $\left(L_{1}=L_{2}=L_{3}=2.5\right)$ and $5 \mathrm{yr}$ for cows $\left(L_{4}=5\right)$. The accuracy $(r)$ was the most conservative accuracy obtained from this study, and $\sigma_{H T}$ is the standard deviation of GEBV of the heat tolerance trait.

Additionally, we investigated the effect of current selection practices (i.e., selection for the Australian
BPI index on responses expected in heat tolerance). To do this, we multiplied the correlation between GEBV for heat tolerance and BPI as already described $\left(r_{H T, B P I}\right)$ by the ratio of genetic standard deviations $\left(\frac{\sigma_{H T}}{\sigma_{B P I}}\right)$, where $\sigma_{H T}$ is the standard deviation of GEBV of the heat tolerance trait, and $\sigma_{B P I}$ is the standard deviation of BPI estimated from 2,357 Holstein and 517 Jersey bulls. If a correlation was considered to be a response to selection on a trait, when the variances were standardized, then this formula essentially scaled the correlation to become the response in heat tolerance per 10-unit change in BPI, which was approximately 1 yr of genetic improvement:

$$
R_{H T, B P I}=r_{H T, B P I} \frac{\sigma_{H T}}{\sigma_{B P I}} 10 .
$$

\section{RESULTS}

\section{Australian Climatic Conditions and Heat Tolerance Phenotypes}

Over the 11-yr period (2003-2013) used in this study, the average daily temperature, relative humidity, and THI in Australia were $15.5 \pm 7.1^{\circ} \mathrm{C}, 70.2 \pm 22.8 \%$, and $59.0 \pm 11.6$, respectively. Mean monthly temperatures and THI were lowest in winter (June-August) and peaked in summer (December-February).

Figure 3 shows the distributions of daily average temperatures, humidity, and THI in dairying regions. It can be seen that, in all dairy farming regions of Australia, cows experienced some degree of heat load and it was variable among regions. For example, in Queensland the median of daily temperatures and THI were $20.7^{\circ} \mathrm{C}$ and 67.3, respectively. Northern Victoria experienced a wide spectrum of weather conditions, with average daily temperatures ranging from -5 to $38^{\circ} \mathrm{C}$ (median $=13^{\circ} \mathrm{C}$ ), and THI ranged from 33.8 to 81.0 (median $=$ 56.6). Each year in Queensland, on average, $108 \mathrm{~d}$ had THI $\geq 70$ and more than half the year had THI $\geq 65$. Cows in other major dairy regions, such as New South Wales, South Australia, and northern Victoria, also experienced high heat load (15-34 d with THI $\geq 70$ per year and $61-107 \mathrm{~d}$ with THI $\geq 65$ per year, respectively; Figure 4).

\section{Genetic Parameters}

The approximate heritability of heat tolerance is presented in Table 2 for milk, fat, and protein, for firstparity data and data combined across 3 parities. In most cases, these values were slightly lower in the first- 

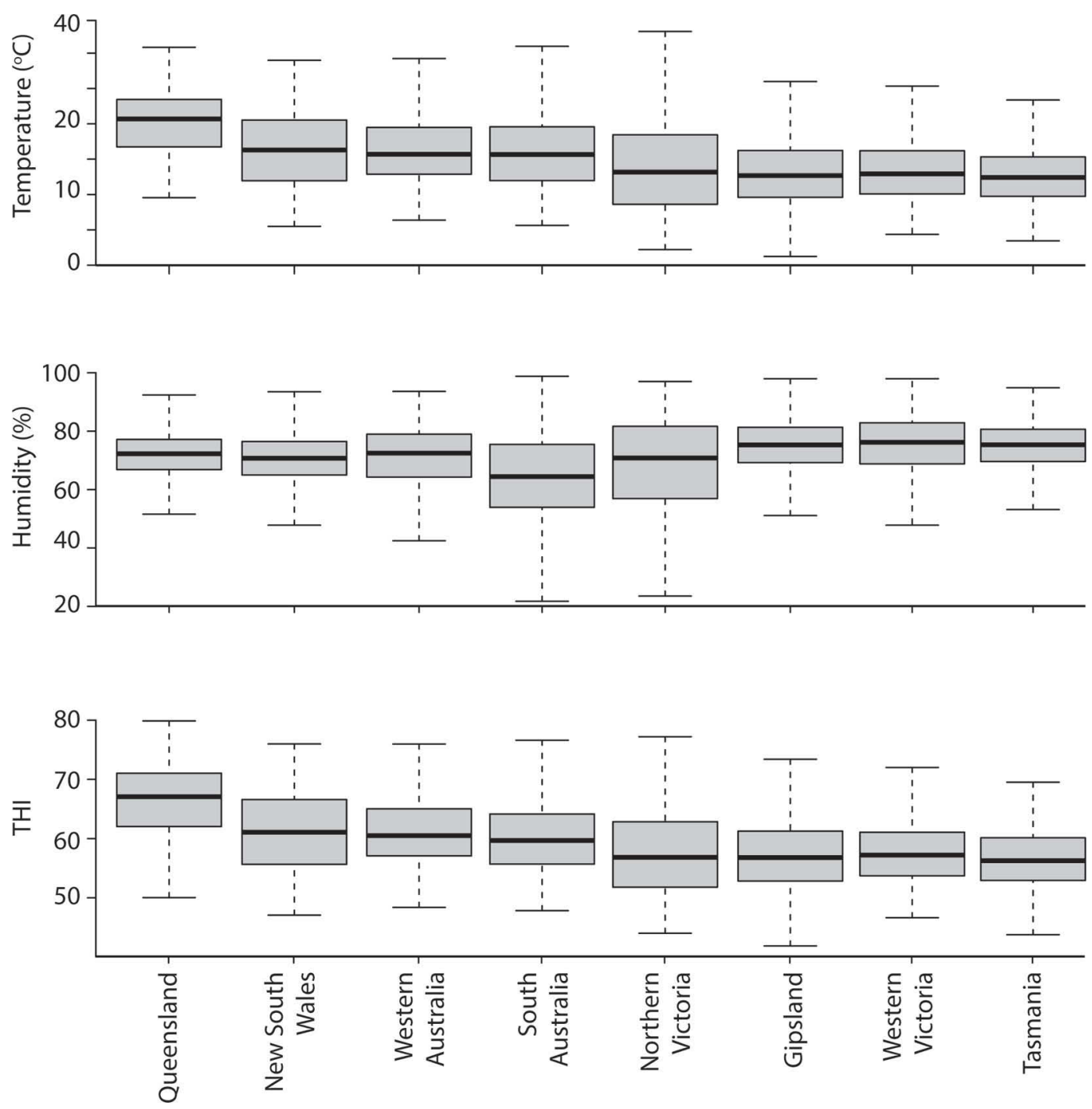

Figure 3. Boxplots showing the distribution of daily average temperature, relative humidity, and temperature-humidity index (THI) in major dairy regions in Australia between 2003 and 2013. The ends of the whiskers of each boxplot represent minimum and maximum of the data, the top and bottom of the box are the first and the third quartiles, and the bold band is the median. Only data from weather stations used in the present study were shown.

parity data set compared with the equivalent variance estimated from combined data. When using the data from the first parity alone, the approximate heritability of heat tolerance to phenotypic variation for milk, fat, and protein yields were $0.19,0.17$, and 0.17 in Holsteins and $0.24,0.18$, and 0.18 in Jerseys, respectively; in the combined data set of the 3 parities, these values were $0.22,0.20$, and 0.23 in Holsteins and $0.33,0.26$, and 0.27 in Jerseys, respectively.

The proportion of variance of DTD for decline in milk, fat, and protein yields with increasing THI in the first parity explained by SNP relative to phenotypic variance were $0.41,0.33$, and 0.32 in Holsteins and 0.47 , 0.43 , and 0.43 in Jerseys, respectively. Correlations of DTD for decline in milk and protein with increasing THI were high (0.86 in Holsteins and $0.86-0.87$ in Jerseys), followed by that between fat and protein (0.54-0.56 in Holsteins and 0.73-0.75 in Jerseys; Table 2 ). We observed an increase in the genetic variance in DTD captured by the SNP when data from the second and third parities were included (Table 3 ).

\section{Accuracies of GEBV}

Accuracies of GEBV for heat tolerance, estimated from correlations of GEBV and DTD in the validation bulls sets, were moderate (Table 4). When only genotyped bulls were included in the reference population 
Table 2. Approximate heritability of heat tolerance, proportion of variance of daughter trait deviations (DTD) explained by SNP markers and correlations between DTD of milk, fat, and protein yield (below diagonal: Holsteins; above diagonal: Jerseys)

\begin{tabular}{|c|c|c|c|c|c|c|c|c|}
\hline Parity & $\begin{array}{l}\text { Traits affected } \\
\text { by heat stress }\end{array}$ & \multicolumn{2}{|c|}{$\begin{array}{l}\text { Approximate heritability } \\
\text { of heat tolerance } \pm \mathrm{SE}\end{array}$} & \multicolumn{2}{|c|}{$\begin{array}{c}\text { Proportion of variance of } \\
\text { DTD explained by SNP } \\
\text { markers } \pm \text { SE }\end{array}$} & \multicolumn{3}{|c|}{ Correlations of DTD } \\
\hline \multirow[t]{2}{*}{1} & Milk yield & $0.19 \pm 0.007$ & $0.24 \pm 0.014$ & $0.41 \pm 0.037$ & $0.47 \pm 0.079$ & - & 0.57 & 0.86 \\
\hline & Fat yield & $0.17 \pm 0.006$ & $0.18 \pm 0.012$ & $0.33 \pm 0.037$ & $0.43 \pm 0.078$ & 0.46 & - & 0.73 \\
\hline \multirow{2}{*}{$1-3$} & Fat yield & $0.20 \pm 0.007$ & $0.26 \pm 0.015$ & $0.34 \pm 0.036$ & $0.51 \pm 0.079$ & 0.45 & - & 0.75 \\
\hline & Protein yield & $0.23 \pm 0.007$ & $0.27 \pm 0.016$ & $0.36 \pm 0.036$ & $0.48 \pm 0.078$ & 0.86 & 0.54 & - \\
\hline
\end{tabular}

(i.e., cows were excluded) and only data from the first parity were used, accuracies of GEBV for heat tolerance measured by decline in milk, fat, and protein yields with increasing THI were $0.48,0.50$, and 0.49 for Holsteins and 0.44, 0.61, and 0.53 for Jerseys, respectively (Figure 4). Improvement in accuracies were achieved when cows were included in the reference population of Holsteins, but not in the case of Jerseys. Surprisingly, no improvements were observed when additional data from the second and the third parities were used, although this may reflect the fact that less data from the second and third parities was available.

\section{Correlations with Other Traits}

Correlations between the GEBV for heat tolerance obtained from the first parity data and the GEBV derived from data from all 3 parities were high $(0.90,0.93$, and 0.92 in Holsteins and 0.98, 0.97, and 0.97 in Jerseys for milk, fat, and protein, respectively). Accordingly, we used heat tolerance GEBV obtained from the first parity data to correlate with ABV of other traits.

The GEBV for heat tolerance were negatively correlated with $\mathrm{ABV}$ for most production traits, with the correlation coefficients ranging from -0.85 to -0.24 in

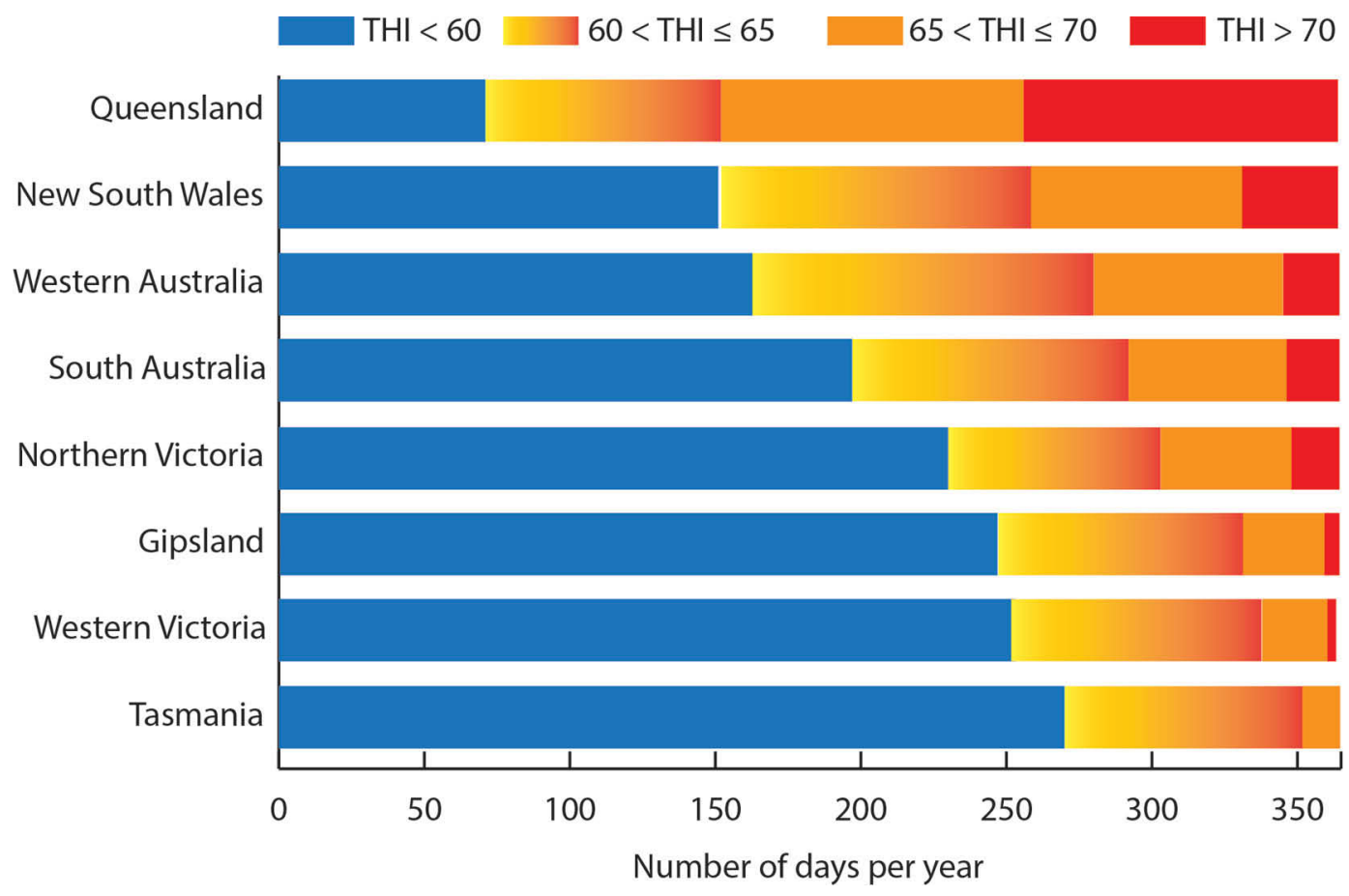

Figure 4. Average number of days per year with temperature-humidity index (THI) $<60,60<\mathrm{THI} \leq 65,65<\mathrm{THI} \leq 70$, and THI $>70$ in dairy farming regions in Australia. 
Table 3. Genetic variance of daughter trait deviations (DTD) captured by SNP (variance component) in the first parity and first, second, and third parities combined

\begin{tabular}{llcc}
\hline Trait & Parity & Holstein & Jersey \\
\hline Milk yield $(\mathrm{L})$ & 1 & 0.0005 & 0.0003 \\
Fat yield $(\mathrm{kg} \times 100)$ & $1-3$ & 0.0011 & 0.0005 \\
& 1 & 0.0063 & 0.0032 \\
Protein yield $(\mathrm{kg} \times 100)$ & $1-3$ & 0.0124 & 0.0106 \\
& 1 & 0.0062 & 0.0021 \\
& $1-3$ & 0.0143 & 0.0090 \\
\hline
\end{tabular}

Holsteins and -0.88 to -0.13 in Jerseys. The correlations between heat tolerance GEBV and fertility ABV were favorable ( 0.29 to 0.39 in Holsteins and 0.15 to 0.27 in Jerseys). Correlations between heat tolerance GEBV and residual survival were close to zero in Holsteins, but slight to moderately negative in Jerseys. A small favorable correlation was noted with feed saved and heat tolerance breeding values in Holsteins, but no clear pattern (across the 3 production traits) was observed in Jerseys (Table 5).

\section{Response to Selection}

The assumptions included in our calculations of response to selection on GEBV for heat tolerance began with the most conservative accuracy level estimated for heat tolerance GEBV (0.39). Table 6 shows that directly selecting on heat tolerance would lead to $+0.004 \mathrm{~L}$ of milk, $+0.00013 \mathrm{~kg}$ of fat, and +0.00013 $\mathrm{kg}$ of protein per unit of THI in Holsteins. The actual response will vary by region, according to units of THI above 60 per year. In regions with high heat load, such as Queensland, where on average each year there were 2,210 units of THI above the THI threshold of 60 in total, then the response to selection in Holsteins would be an additional $8.3 \mathrm{~L}$ of milk, $0.28 \mathrm{~kg}$ of fat, and $0.28 \mathrm{~kg}$ of protein per year. In Jerseys under average Queensland conditions, an additional $5.7 \mathrm{~L}$ of milk, 0.20 $\mathrm{kg}$ of fat, and $0.16 \mathrm{~kg}$ of protein per year was predicted. In northern Victoria, with an average of 635 units of THI above the threshold per year, the gain expected in Holsteins would be an additional $2.4 \mathrm{~L}$ of milk, $0.08 \mathrm{~kg}$ of fat, and $0.08 \mathrm{~kg}$ of protein per year, and in Jerseys we predict an additional $1.6 \mathrm{~L}$ of milk, $0.06 \mathrm{~kg}$ of fat, and $0.05 \mathrm{~kg}$ of protein. Current selection practices (i.e., selection on BPI) would result in a very slight decrease in heat tolerance, leading to a very small reduction in the rate of increase for yield; for example, $0.001 \mathrm{~L}$ of milk in Holsteins (Table 6).

\section{DISCUSSION}

Our study demonstrated that by using field data on milk production records together with publicly available climate data and dense SNP markers, it was possible to

Table 4. Correlations between daughter trait deviations (DTD) and genomic estimated breeding values (GEBV) of 435 Holstein and 135 Jersey validation sires, as well as accuracies of GEBV for heat tolerance (correlations divided by the square-root of the proportion of variance of DTD explained by SNP) using 632,003 SNP panel

\begin{tabular}{|c|c|c|c|c|c|}
\hline Breed & $\begin{array}{l}\text { Reference } \\
\text { (parity, number of sires and cows) }\end{array}$ & $\begin{array}{l}\text { Validation } \\
\text { (parity) }\end{array}$ & $\begin{array}{l}\text { Production traits } \\
\text { affected by heat stress }\end{array}$ & Correlation & Accuracy \\
\hline \multirow[t]{8}{*}{ Holstein } & Parity $1,2,300$ sires & 1 & Milk yield & 0.31 & 0.48 \\
\hline & \multirow[t]{3}{*}{ Parity $1,2,300$ sires $+2,189$ cows } & \multirow[t]{3}{*}{1} & Milk yield & 0.29 & 0.45 \\
\hline & & & Fat yield & 0.32 & 0.56 \\
\hline & & & Protein yield & 0.32 & 0.57 \\
\hline & Parity $1,2,300$ sires $+2,189$ cows & $1-3$ & Protein yield & 0.29 & 0.42 \\
\hline & \multirow[t]{3}{*}{ Parity $1-3,2,300$ sires $+2,189$ cows } & \multirow[t]{3}{*}{$1-3$} & Milk yield & 0.31 & 0.43 \\
\hline & & & Fat yield & 0.33 & 0.46 \\
\hline & & & Protein yield & 0.35 & 0.51 \\
\hline \multirow[t]{7}{*}{ Jersey } & \multirow[t]{3}{*}{ Parity 1,575 sires } & \multirow[t]{3}{*}{1} & Milk yield & 0.30 & 0.44 \\
\hline & & & Fat yield & 0.40 & 0.61 \\
\hline & & & Protein yield & 0.35 & 0.53 \\
\hline & Parity 1,575 sires $+1,188$ cows & $1-3$ & Protein yield & 0.32 & 0.46 \\
\hline & \multirow[t]{3}{*}{ Parity $1-3,575$ sires $+1,188$ cows } & \multirow[t]{3}{*}{$1-3$} & Milk yield & 0.35 & 0.49 \\
\hline & & & Fat yield & 0.39 & 0.55 \\
\hline & & & Protein yield & 0.36 & 0.52 \\
\hline
\end{tabular}


derive genomic predictions for heat tolerance with an accuracy of 0.39 to 0.57 in Holsteins and 0.44 to 0.61 in Jerseys. These accuracies suggest genomic selection is a promising approach to accelerate genetic gains for heat tolerance. Although the accuracies of GEBV for heat tolerance were not as high as the accuracies of production traits, where accuracies of up to 0.8 have been achieved (Wiggans et al., 2011), they are comparable to other economically important traits, such as DM feed intake (accuracies of 0.40-0.50; de Haas et al., 2012).

Although the accuracies of GEBV for heat tolerance we report here would enable gains to be made for this trait, higher accuracies are desirable, as this would result in greater gain. One way of achieving higher accuracies would be to increase the size of the reference population. That is, genotyping more sires and cows for which the heat tolerance phenotype can be derived. In our study, slight improvements in accuracies of GEBV were achieved when cows were included in the reference populations of Holsteins, but not in Jerseys. This is likely due to the small number of genotyped cows that were added to the reference $(2,189$ Holstein and 1,188 Jersey cows). Bapst et al. (2013) also reported a minimal improvement in accuracies for GEBV of production and other traits in Swiss Brown Swiss when adding 1,000 cows to the reference population of 4,000 sires. In other cases where the number of cows added was large (Calus et al., 2013; Thomasen et al., 2014), the increase in accuracies of GEBV were significant. Australian genomic evaluations for routinely evaluated traits include 10,000 cows chosen to have excellent herd-recording information in the reference population, and Pryce et al. (2013) reported an increase of reliability of genomic prediction between 4 and $8 \%$ after adding these cows to the reference depending on the trait. Similarly, Kemper et al. (2015) also observed a 4 to $5 \%$ increase in accuracy of prediction for production and other traits when including 8,478 Holstein and 3,917 Jersey cows in a multibreed reference population. Results from these studies are encouraging, suggesting that accuracies of genomic evaluation for heat tolerance should improve as more and more cows are added to the reference population. The optimal composition of the genomic reference population (i.e., the ratio of genotyped bulls to genotyped cows) to maximize the accuracy of genomic prediction is not clear. However, as the technology of genomic selection matures in the dairy industry, it appears likely that there will be comparatively fewer genotyped bulls with large progeny groups compared with genotyped cows (Gonzalez-Recio et al., 2014). Therefore, adding large numbers of cows with the heat tolerance phenotype may become the way to increase accuracies of the heat tolerance GEBV in the future. 
Table 6. Direct response to selecting on heat tolerance genomic estimated breeding values (GEBV) on milk production traits in Holsteins and Jerseys per unit of temperature-humidity index (THI) and correlated response of heat tolerance to selection on the Balanced Performance Index (BPI)

\begin{tabular}{llccc}
\hline Breed & Trait & $\begin{array}{c}\text { Genetic standard deviation } \\
\text { of heat tolerance GEBV }\end{array}$ & $\begin{array}{c}\text { Direct response } \\
\text { per unit of THI }\end{array}$ & $\begin{array}{c}\text { Correlated response } \\
\text { with BPI (per year) }\end{array}$ \\
\hline Holstein & Milk yield (L) & 0.023 & 0.004 & -0.0010 \\
& Fat yield $(\mathrm{kg} \times 100)$ & 0.080 & 0.013 & -0.0009 \\
Jersey & Protein yield $(\mathrm{kg} \times 100)$ & 0.079 & 0.013 & -0.0047 \\
& Milk yield $(\mathrm{L})$ & 0.016 & 0.003 & -0.0036 \\
& Fat yield $(\mathrm{kg} \times 100)$ & 0.056 & 0.009 & -0.0003 \\
& Protein yield $(\mathrm{kg} \times 100)$ & 0.046 & 0.007 & -0.0023 \\
\hline
\end{tabular}

Surprisingly, no significant increases in accuracies of GEBV for heat tolerance were observed when data from the second and third parities were included in the analyses. This could reflect the fact that we used a repeated records model for the random regressions for each cow, and fewer records in later parities were used. Ideally, a multitrait model would be used to derive more accurate estimates of cow slope on THI when data from the second and third parities were included. This is possible, although the computational demands with multiple lactations and a random regression model on THI would be considerable.

Other methodological improvements could be investigated to improve accuracy of GEBV for heat tolerance. In the present study we adopted a 2-step approach to estimate genomic breeding values for heat tolerance. A one-step model would allow all information (phenotype, pedigree, and genomics) to be used simultaneously (Aguilar et al., 2010), which could result in more accurate estimates of breeding value, particularly as the polygenic (pedigree) component could capture variance not captured by the SNP.

In the current study, we did model an interaction between stage of lactation and a fixed regression on THI. Cows at early lactation are more likely to be susceptible to heat stress (Moran, 2005). Therefore, incorporating this interaction in the model may result in more accurate GEBV for heat tolerance. A further improvement could be to fit random regressions instead of fixed regressions to DIM and other covariates (Brügemann et al., 2011); attempts were made in this regard, but unfortunately convergence of parameters was not achieved with these models.

In the present study, we used DTD as the dependent variable to derive GEBV for heat tolerance. Another possibility would be to use deregressed breeding values. Using deregressed breeding values as the dependent variable could have advantages in some situations; for example, if heat tolerance information was combined across countries to improve accuracy of GEBV.

Heat tolerance is a complex trait, and decline in production is only one potential indicator phenotype for this trait. One possible alternative way of analysis would be to use an individual threshold at which production begins to decline, as well as the rate of decline, as phenotypes. One complication with the simple model we have used, with a fixed threshold, may be that variation of thresholds really exists among cows and a common threshold is assumed, this could bias the estimation of individual slopes. For example, the slope of response to heat of animals with a higher than the assumed common threshold will be underestimated, and the slope for animals with a lower threshold will be overestimated. This could inflate the estimated overall variability in slopes, and therefore reliabilities of GEBV in routine evaluations (as calculated from the inverse of the coefficient matrix). In addition, Sánchez et al. (2009) found a correlation of 0.76 between the EBV for slopes estimated using a model that allows for different thresholds for each cow with that from a simpler model that assumes a common threshold for all animals. This suggests selection for one of these traits would lead to favorable response in heat tolerance for the other, but some reranking may occur.

The accuracy of the GEBV will be limited by the fact that the use of test-day weather records captures only a proportion of the variation due to heat stress because no consideration is given to variability between test days (Misztal et al., 2006). Other phenotypes for heat tolerance, such as change in rectal temperatures with increasing THI or daily milk production and daily THI records, may be more accurate phenotypes for heat tolerance and have greater genetic variation; however, such measures are difficult to collect on a large scale.

Some other candidate measures, such as effects on fertility, should also be considered; however, the data available is more limited than for production. Other traits, such as appetite (quantified as DMI), are also likely to be affected by heat stress; however, at present it is only possible to measure feed intakes in a research setting. Although, it may be possible to get more records by looking at phenotypes that can be quantified in milk. For example, a potential predictor for heat tolerance is fatty acid profile in milk. Fatty acid profiles 
can be measured on a large scale through mid-infrared spectroscopy of milk samples, and a recent study suggests changes in this profile with heat stress (Hammami et al., 2015). Further work is required to determine if this trait is suitable as a phenotype for deriving GEBV for heat tolerance.

We observed that ABV of yield traits and heat tolerance GEBV are antagonistically correlated. That is, when animals are selected for better yields, ability to tolerate heat can decline in the next generations. This confirms the findings from previous study on heat tolerance in dairy cattle (Ravagnolo and Misztal, 2000; Bernabucci et al., 2014). In this study, we analyzed data from all 3 parities in a single model and observed strong negative correlations between heat tolerance and milk production traits. These correlations are stronger compared with those obtained from the approach where data from the 3 parities were analyzed separately and solutions were averaged for each cow (data not shown). This is likely a result of greater genetic variation in heat tolerance captured when all parities were analyzed together; however, it does indicate sensitivity of results to different models.

Selection for improved heat tolerance should be implemented simultaneously with selection for key dairy traits in a selection index framework, particularly given the unfavorable correlation between heat tolerance and production. To achieve this, the net economic effect of improving heat tolerance in the target region (how many heat stress events are experienced per year and how severe are they) is required. To some extent, the selection that has been occurring recently for improved fertility will have favored selection of more heat-tolerant animals, or at least stemmed a decline in heat tolerance. Misztal et al. (2006) also observed that heattolerant cows had higher daughter pregnancy rates. It is also important to consider that losses due to poor heat tolerance can be greater than simply a decline in milk production and can include cessation of lactation, poor health and fertility, and, in extreme cases, loss of animals.

\section{CONCLUSIONS}

We have demonstrated that heat tolerance in dairy cattle could be improved using genomic selection. Although the accuracies of GEBV for heat tolerance we reported here would enable gains to be made for this trait, we expect accuracy will improve as the size of the reference population is expanded. If heat tolerance is included in a multitrait selection index, correlations with other production and functional traits and, ultimately, its net economic effect, given current and predicted future incidence of heat stress events, should be considered to achieve a balanced outcome.

\section{ACKNOWLEDGMENTS}

The authors thank Department of Agriculture of Australia (Canberra, Australia) for funding this project ("Novel strategies to breed dairy cattle for adaptation and reduced methane emissions") and the Australia Dairy Herd Improvement Scheme (Melbourne, Australia) for providing production data. We thank two anonymous reviewers for their constructive comments.

\section{REFERENCES}

Aguilar, I., I. Misztal, D. L. Johnson, A. Legarra, S. Tsuruta, and T. J. Lawlor. 2010. Hot topic: A unified approach to utilize phenotypic, full pedigree, and genomic information for genetic evaluation of Holstein final score. J. Dairy Sci. 93:743-752.

Aguilar, I., I. Misztal, and S. Tsuruta. 2009. Genetic components of heat stress for dairy cattle with multiple lactation. J. Dairy Sci. 92:5702-5711.

Armstrong, D. V. 1994. Heat stress interaction with shade and cooling. J. Dairy Sci. 77:2044-2050.

Bapst, B., F. R. Seefried, A. Bieber, H. Simianer, and B. Gredler. 2013. Effect of cows in reference population: First results in Swiss Brown Swiss. Interbull Bull. 47:187-191.

Beede, D. K., and R. J. Collier. 1986. Potential nutritional strategies for intensively managed cattle during thermal stress. J. Anim. Sci. 62:543-554.

Bernabucci, U., S. Biffani, L. Buggiotti, A. Vitali, N. Lacetera, and A. Nardone. 2014. The effects of heat stress in Italian Holstein dairy cattle. J. Dairy Sci. 97:471-486.

Bohmanova, J., I. Misztal, and J. B. Cole. 2007. Temperature-humidity indices as indicators of milk production losses due to heat stress. J. Dairy Sci. 90:1947-1956.

Browning, B. L., and S. R. Browning. 2009. A unified approach to genotype imputation and haplotype-phase inference for large data sets of trios and unrelated individuals. Am. J. Hum. Genet. 84:210-223.

Brügemann, K., E. Gernand, U. U. von Borstel, and S. König. 2011. Genetic analyses of protein yield in dairy cows applying random regression models with time-dependent and temperature $\mathrm{x}$ humidity-dependent covariates. J. Dairy Sci. 94:4129-4139.

Calo, L. L., R. E. McDowell, L. Dale Van Vleck, and P. D. Miller. 1973. Genetic aspects of beef production among Holstein-Friesians pedigree selected for milk production. J. Anim. Sci. 37:676-682.

Calus, M. P. L., Y. de Haas, and R. F. Veerkamp. 2013. Combining cow and bull reference populations to increase accuracy of genomic prediction and genome-wide association studies. J. Dairy Sci. 96:6703-6715.

CSIRO and BoM. 2014. State of the Climate 2014. CSIRO, Melbourne, Australia.

de Haas, Y., M. P. L. Calus, R. F. Veerkamp, E. Wall, M. P. Coffey, H. D. Daetwyler, B. J. Hayes, and J. E. Pryce. 2012. Improved accuracy of genomic prediction for dry matter intake of dairy cattle from combined European and Australian data sets. J. Dairy Sci. 95:6103-6112.

Erbe, M., B. J. Hayes, L. K. Matukumalli, S. Goswami, P. J. Bowman, C. M. Reich, B. A. Mason, and M. E. Goddard. 2012. Improving accuracy of genomic predictions within and between dairy cattle breeds with imputed high-density single nucleotide polymorphism panels. J. Dairy Sci. 95:4114-4129.

Garrick, D. J., J. F. Taylor, and R. L. Fernando. 2009. Deregressing estimated breeding values and weighting information for genomic regression analyses. Genet. Sel. Evol. 41:55. 
Gilmour, A. R., B. J. Gogel, B. R. Cullis, and R. Thompson. 2009. ASReml User Guide Release 3.0. VSN International Ltd., Hemel Hempstead, UK.

Gonzalez-Recio, O., M. P. Coffey, and J. E. Pryce. 2014. On the value of the phenotypes in the genomic era. J. Dairy Sci. 97:7905-7915.

Haile-Mariam, M., M. J. Carrick, and M. E. Goddard. 2008. Genotype by environment interaction for fertility, survival, and milk production traits in Australian dairy cattle. J. Dairy Sci. 91:4840-4853.

Haile-Mariam, M., and J. E. Pryce. 2012. Advantages of using lactation length, mating and pregnancy data to improve the genetic evaluation of fertility based on calving interval in dairy cows. Pages 298-301 in Australasian Dairy Science Symposium 2012 Proceedings. Dairy Australia and Victorian Department of Primary Industries, Melbourne.

Hammami, H., J. Bormann, N. M'hamdi, H. H. Montaldo, and N. Gengler. 2013. Evaluation of heat stress effects on production traits and somatic cell score of Holsteins in a temperate environment. J. Dairy Sci. 96:1844-1855.

Hammami, H., J. Vandenplas, M.-L. Vanrobays, B. Rekik, C. Bastin, and N. Gengler. 2015. Genetic analysis of heat stress effects on yield traits, udder health, and fatty acids of Walloon Holstein cows. J. Dairy Sci. 98:4956-4968.

Hayes, B. J., P. J. Bowman, A. J. Chamberlain, K. Savin, C. P. van Tassell, T. S. Sonstegard, and M. E. Goddard. 2009. A validated genome wide association study to breed cattle adapted to an environment altered by climate change. PLoS ONE 4:e6676.

Hayes, B. J., M. Carrick, P. Bowman, and M. E. Goddard. 2003. Genotype x environment interaction for milk production of daughters of Australian dairy sires from test-day records. J. Dairy Sci. 86:3736-3744.

Hazel, L. N. 1943. The genetic basis for constructing selection indexes. Genetics 28:476-490.

Kemper, K. E., C. M. Reich, P. J. Bowman, C. J. van der Jagt, A. J. Chamberlain, B. A. Mason, B. J. Hayes, and M. E. Goddard. 2015. Improved precision of QTL mapping using a nonlinear Bayesian method in a multi-breed population leads to greater accuracy of cross-breed genomic predictions. Genet. Sel. Evol. 47:29.

Lush, J. L. 1945. Animal Breeding Plans. 3rd ed. Iowa State University Press, Ames.

Miglior, F., B. L. Muir, and B. J. Van Doormaal. 2005. Selection indices in Holstein cattle of various countries. J. Dairy Sci. 88:12551263.
Misztal, I., J. Bohmanova, M. Freitas, S. Tsuruta, H. D. Norman, and T. J. Lawlor. 2006. Issues in genetic evaluation of dairy cattle for heat stress. In Proc. 8th World Congress on Genetics Applied to Livestock Production, Belo Horizonte, MG, Brazil. Instituto Prociencia, Minas Gerais, Brazil.

Moran, J. 2005. Tropical Dairy Farming: Feeding Management for Small Holder Dairy Farmers in the Humid Tropics. Landkinks Press, Clayton, Australia.

Pryce, J. E., M. Blake, K. E. Davis, and D. S. Beggs. 2013. Challenges of health data recording-An Australian perspective. ICAR 2013 Technical Meeting Aarhus, Denmark. International Committee for Animal Recording, Rome, Italy.

Pryce, J. E., O. Gonzalez-Recio, G. Nieuwhof, W. J. Wales, M. P. Coffey, B. J. Hayes, and M. E. Goddard. 2015. Definition and implementation of a breeding value for feed efficiency in dairy cows. J. Dairy Sci. 98:7340-7350.

Ravagnolo, O., and I. Misztal. 2000. Genetic component of heat stress in dairy cattle, parameter estimation. J. Dairy Sci. 83:2126-2130.

Ravagnolo, O., and I. Misztal. 2002. Effect of heat stress on nonreturn rate in Holsteins: fixed-model analyses. J. Dairy Sci. 85:3101-3106.

Sánchez, J. P., I. Misztal, I. Aguilar, B. Zumbach, and R. Rekaya. 2009. Genetic determination of the onset of heat stress on daily milk production in the US Holstein cattle. J. Dairy Sci. 92:40354045.

St-Pierre, N. R., B. Cobanov, and G. Schnitkey. 2003. Economic losses from heat stress by US livestock industries. J. Dairy Sci. 86(Suppl.):E52-E77.

Thomasen, J. R., A. C. Sørensen, M. S. Lund, and B. Guldbrandtsen. 2014. Adding cows to the reference population makes a small dairy population competitive. J. Dairy Sci. 97:5822-5832.

Wiggans, G. R., P. M. VanRaden, and T. A. Copper. 2011. The genomic evaluation system in the United States: Past, present, future. J. Dairy Sci. 94:3202-3211.

Yang, J., B. Benyamin, B. P. McEvoy, S. Gordon, A. K. Henders, D. R. Nyholt, P. A. Madden, A. C. Heath, N. G. Martin, G. W. Montgomery, M. E. Goddard, and P. M. Visscher. 2010. Common SNPs explain a large proportion of the heritability for human height. Nat. Genet. 42:565-569.

Yousef, M. K. 1985. Stress Physiology in Livestock. CRC Press, Boca Raton, FL. 